\title{
ADIE'S PUPIL DURING MIGRAINE ATTACK: A CASE REPORT
}

\author{
Amar Kanti Chakma ${ }^{1}$, Arindam Datta ${ }^{2}$, Debasis Datta ${ }^{3}$, Chandini Reang ${ }^{4}$
}

\section{HOW TO CITE THIS ARTICLE:}

Amar Kanti Chakma, Arindam Datta, Debasis Datta, Chandini Reang. "Adie's Pupil during Migraine Attack: A Case Report". Journal of Evolution of Medical and Dental Sciences 2014; Vol. 3, Issue 15, April 14; Page: 4072 4074, DOI: $10.14260 /$ jemds/2014/2401

\begin{abstract}
Association of migraine and tonic pupil has been reported very rarely. We reported a young female with symptoms of migraine who developed a mydriatic pupil in one of her attacks. The pupil was unresponsive to light with little response to near reflex. In $0.125 \%$ pilocarpine test affected pupil responded significantly and tonic pupil was diagnosed. We discussed possible mechanisms and reviewed previous cases with the same diagnosis. Evidences show that this association may be caused by infarction of parasympathetic fibers secondary to prolonged vasospasm which sometimes occurs in migraine.
\end{abstract}

KEYWORDS: Adie's pupil, tonic pupil, migraine.

INTRODUCTION: Adie's (tonic) pupil is defined as a mydriatic pupil, which is unresponsive to light and is moderately responsive to accommodation. The damage to postganglionic parasympathetic fibers may cause this syndrome. Diagnosis is established with rapid miotic response of affected pupil to $0.125 \%$ pilocarpine drop. ${ }^{1}$ Diseases such as giant cell arteritis, Sjogren's syndrome, malignancies, paraneoplastic anti-hu antibody syndrome and infections have been reported to be associated with tonic pupil.2-4 There are few reports on occurrence of Adie's pupil during a migraine attack 1,5-7. Here we described a patient with a history of migraine who develops Adie's pupil during one of her attacks.

CASE REPORT: A 27-year-old female presented with the alteration of the size of her pupil. She also noted a concomitant throbbing headache mostly behind her left eye as well as dysesthesia of the face on the same side which was accompanied by nausea, photophobia, pallor and dry mouth. The headache was present for years with a frequency of every two days. The episodes took about 24 hours to improve without any treatment. The change in the size of her pupil had occurred during one of the attacks and had not been subsided after relief of the headache. She also complained of blurred vision mainly at the time of reading. Her pain was relieved with manual pressure on the temporal area and also vomiting. No medication overuse was noted.

A positive family history was present for migraine. Drug, habit and past histories were unremarkable other than a history of similar headaches for several years. Her general physical examination was unremarkable. In the neurological examination left pupil was dilated (of about 5 $\mathrm{mm}$ ) (fig-1) and round in shape and the right pupil was midsize (3.5 $\mathrm{mm}$ ). There was no response to light in the left pupil. No abnormalities in the eye movement as well as fundal examination were detected. In the examination of near reflex, the size of left pupil reduced slowly but not completely.

Deep tendon reflexes were $2+$ in all extremities. Perimetry and examination of visual acuity were normal. Other neurological examinations revealed no abnormality. Cell count, sedimentation rate, and routine blood chemistries, were normal and anti-Ro, anti-La, anti RNP, ELISA for Retrovirus I \& II and VDRL were negative. Brain MRI showed no abnormality. In the $0.125 \%$ pilocarpine test 


\section{CASE REPORT}

there was a significant response in the left pupil with remarkable reduction of its size to about $3 \mathrm{~mm}$ after about 20 minutes (fig. 2). A diagnosis of tonic pupil and migraine without aura (using IHC criteria) was established. Ergotamine with Paracetamol tablet for the headache and

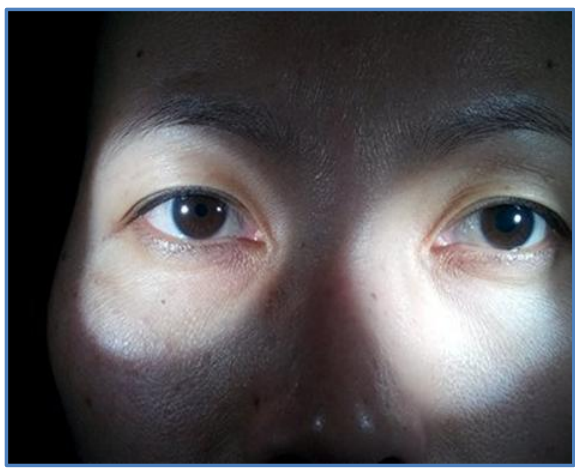

\section{Fig. 1: Picture showing dilated pupil in left}

Flunarazine $10 \mathrm{mg}$ daily was prescribed and the patient's headache improved significantly. The size of the pupil becomes normal within two days. The problem for near vision becomes corrected.

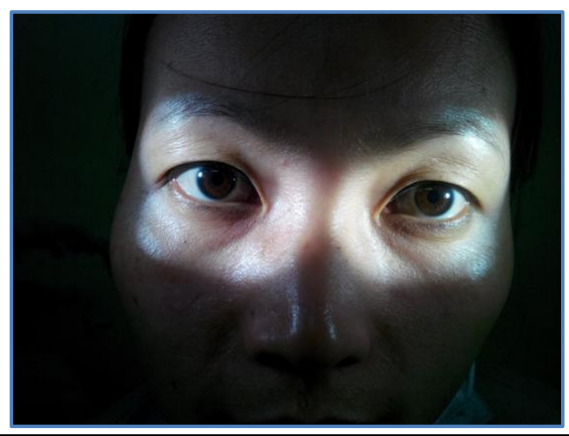

Fig. 2: Picture showing normal pupil after $0.125 \%$ pilocarpine drops

DISCUSSION: Massey in 1981 noted the possible link between migraine and tonic pupil. He studied 22 patients with tonic pupil and identified the personal and family history of migraine in eight and nine of them respectively. ${ }^{8}$ However, the simultaneous occurrence of migraine and tonic pupil was not reported until 1995, when Purvin reported the first case of co-occurrence of migraine and Adie's pupil. Using Pubmed and Scopus engines and search terms of "tonic pupil" or "Adie's pupil" And "migraine" or "headache" we only identified four previous cases of concomitant migraine and tonic pupil.6

There was also an additional case in which association of hemicranias and tonic pupil was reported..$^{9}$ The underlying mechanism of the link between tonic pupil and migraine remains to be established. In Adie's pupil, denervation of postganglionic parasympathetic fibers occurs, leading to supersensitive response to cholinergic agonists.

Sometimes it may be part of a syndrome, the Holmes Adie's syndrome in which, tonic pupil is associated with absent or reduced deep tendon reflexes.10 Any damage to postganglionic parasympathetic fibers can lead to manifestations of Adie's pupil. These can be inflammation, 
autoantibodies, dysautonomia (as in Harlequin and Ross syndrome) or ischemia. ${ }^{10}$ Although pallor and dry mouth in our patient make the diagnosis of dysautonomia a possibility, ischemic damage may be a more suitable diagnosis.

Ischemia occurs in migraine, particularly in prolonged attacks and it is possible that, a prolonged vasospasm occurred in our patient and caused infarction of the postganglionic fibers leading to permanent dysfunction of the left pupil.6 Although we and several others, proposed ischemia as the possible cause, more studies are needed in this regard to its rarity.

\section{REFERENCES:}

1. Iannetti $\mathrm{P}$ et al. Residual and persistent Adie's pupil after pediatric ophthalmoplegic migraine. Pediatr Neurol. 2009; 41(3):204-6.

2. Muller NG, Prass K, Zschenderlein R. Anti-hu antibodies, sensory neuropathy, and Holmes-Adie Syndrome in a patient with seminoma. Neurology. 2005; 64(1):164-5.

3. Bachmeyer $\mathrm{C}$ et al. Adie syndrome as the initial sign of primary Sjogren syndrome. Am J Ophthalmol. 1997; 123(5):691-2.

4. Foroozan R et al. Tonic pupils from giant cell arteritis. Br J Ophthalmol. 2003; 87 (4):510-2.

5. Jacome de. Status migrainosus and Adie's syndrome. Headache. 2002; 42 (8):793-5.

6. Purvin VA. Adie's tonic pupil secondary to migraine. J Neuroophthalmol. 1995; 15(1):43-4.

7. Drouet A et al. Adie's tonic pupil and migraine: a chance association? J Fr Ophtalmol. 2008; 31(2):e5.

8. Massey EW. Pupillary dysautonomia and migraine: is Adie's pupil caused by migraine? Headache. 1981; 21(4):143-6.

9. Rodrigues $\mathrm{Cl}$ et al. Holmes-Adie pupil in a patient with hemicrania: a spectrum of a multifocal autonomic dysfunction? Arq Neuropsiquiatr. 2008; 66(2b):423-4.

10. Shin RK et al. Ross syndrome plus: beyond horner, Holmes-Adie, and harlequin. Neurology. 2000; 55(12):1841-6.

\section{AUTHORS:}

1. Amar Kanti Chakma

2. Arindam Datta

3. Debasis Datta

4. Chandini Reang

\section{PARTICULARS OF CONTRIBUTORS:}

1. Associate Professor, Department of Ophthalmology, Tripura Medical College, Hapania, Agartala.

2. Associate Professor, Department of Medicine, Tripura Medical College \& Dr. BRAM Teaching Hospital, Hapania, Agartala.

3. Professor and HOD, Department of Ophthalmology, Tripura Medical College, Agartala.
4. Medical Officer, Department of Ophthalmology, Tripura Medical College \& Dr. BRAM Teaching Hospital, Hapania, Agartala.

\section{NAME ADDRESS EMAIL ID OF THE} CORRESPONDING AUTHOR:

Dr. Amar Kanti Chakma, Department of Ophthalmology, Tripura Medical College \& Dr. BRAM Teaching Hospital, Hapania, Agartala - 14.

E-mail: amarkanti@yahoo.com

Date of Submission: 18/03/2014.

Date of Peer Review: 19/03/2014.

Date of Acceptance: 25/03/2014.

Date of Publishing: 08/04/2014. 